\title{
USING GLOBAL VIRTUAL TEAMS TO SUPPORT A SUSTAINABILITY MINDSET IN ENGINEERING EDUCATION
}

\author{
Anuli Ndubuisi and James Slotta \\ Ontario Institute for Studies in Education, University of Toronto \\ anuli.ndubuisi@mail.utoronto.ca, jslotta@gmail.com
}

\begin{abstract}
In an increasingly interconnected economy, future engineers require a sustainability mindset, which necessitates a global perspective, to enable them to work together with diverse partners to tackle the world's problems in a sustainable manner. This study explores engineering students' development of intercultural competencies within the context of culturally diverse global virtual team projects. We report on two consecutive iterations of an Intercultural Competency Module (ICM) delivered within a global virtual team project setting, in which engineering students are engaged in collaborative technical projects. Each study iteration comprised of a presurvey to gain insights into student's prior knowledge and cultural background and a post-survey to determine students' perceptions of their intercultural learning and experiences. Employing a mixed-methods approach, we found that blending ICM with global virtual team projects was a successful approach for helping engineering students acquire international experience and develop intercultural competencies in addition to technical engineering knowledge.
\end{abstract}

Keywords: Global Virtual Teams, Intercultural Competence, Sustainability Mindset, Global Perspectives, Global Engineering Education, International Experience, Global Competence, Intercultural Communication

\section{INTRODUCTION}

As the global economy becomes increasingly uncertain, interconnected, and multifaceted, future engineers require a sustainability mindset to help them address the world's global challenges in a way that contributes to sustainable development [4] [17]. This entails a global perspective and the ability to collaborate with different stakeholders, often from diverse cultures [9] [15] [14]. Engineering institutions have traditionally helped students achieve a global engineering education through study abroad programs, recruitment of international students, international placements, student exchange programs, as well as research abroad [16]. However, common barriers to the growth of these programs have been scalability constraints, political and safety concerns of host countries, high financial requirements, restrictions from academic planning schedule, inflexibility of students' time and the recent COVID-19 health crisis [5][12]. A 2020 annual report by one of Canada's top engineering institutions found over $40 \%$ reduction in engineering students' uptake of international placement positions between 2018/19 and 2019/20 academic years [3]. Likewise, an annual Open Doors' survey of over 700 higher education providers in the United States showed a $43 \%$ decrease in new international student enrolments in the fall of 2020 [6]. Thus, it is pertinent for engineering institutions to explore ways to leverage information communication and technological solutions to advance global engineering education in a scalable manner. This can help students acquire global perspectives and a sustainability mindset that they will need to succeed in a complex and interconnected global society. This study examines engineering students' intercultural competencies and supports their development of those competencies within the context of a global engineering project where they work with geographically distributed and culturally diverse team members.

\section{A Global VirTual TeAM (GVT) INITIATIVE}

In 2019, a global virtual team (GVT) learning initiative was setup with the aim of providing a scalable approach to promoting engineering students' international knowledge $\&$ experiences. The GVT program consisted of an Intercultural Competency Module (ICM), in which students explored the importance of diverse cultures and voices in virtual teams, and a technical research component, managed by the supervising faculty members, in which globally distributed multidisciplinary students were engaged in authentic engineering projects. We report on two successive iterations of the GVT program, where engineering students were engaged in the ICM around collaborative technical projects. 


\subsection{Theoretical Perspectives}

The design of the InVEST program was guided by the theoretical perspective of social constructivism [1] and the Community of Inquiry (COI) framework [11] to create a student-centered learning and an effective online educational experience. In addition, design efforts were guided by an instructional design model called Knowledge Community and Inquiry (KCI) [8] which provides a set of principles to engage students in a learning community curriculum. Guided by the KCI model, students' inquiry learning around virtual team working concepts was facilitated based on the ideas and perspectives of their peers with a focus on progressing the community towards the learning goals.

\subsection{Design Based Research}

This study employed a design-based research (DBR) methodology, which allowed for the iterative design and improvement of the ICM curriculum. Each iteration began with a pre-survey to understand students' initial knowledge and cultural orientation and a post-survey to assess their intercultural experiences and learning. Here, we review our designs of each iteration and discuss how we improved student learning experiences that included the development of intercultural competencies and global perspectives.

\subsection{Participants}

Participants from the two studies were multidisciplinary engineering students from various universities who selfselected to collaborate virtually with international peers from partner institutions on technical research projects to solve specific problems, identified by faculty, industry practitioners or representatives of other institutions. Figure 1 shows participants' profile for the two study iterations.

\begin{tabular}{lcc}
\hline $\begin{array}{l}\text { Number of } \\
\text { students }\end{array}$ & $\begin{array}{c}\text { lst Study } \\
\text { Iteration }\end{array}$ & $\begin{array}{c}\text { 2nd Study } \\
\text { Iteration }\end{array}$ \\
\hline $\begin{array}{l}\text { Virtual } \\
\text { team sizes }\end{array}$ & 20 & 17 \\
\hline $\begin{array}{l}\text { Degree } \\
\text { type }\end{array}$ & $\begin{array}{c}\text { undergraduate } \\
\text { to graduate } \\
\text { ratio is } \\
\text { roughly } 60 \% \\
\text { to } 40 \%\end{array}$ & $\begin{array}{c}\text { undergraduate } \\
\text { to graduate } \\
\text { ratio is roughly } \\
70 \% \text { to } 30 \%\end{array}$ \\
\hline $\begin{array}{l}\text { Age range } \\
\text { language } \\
\text { proficiency }\end{array}$ & $\begin{array}{c}20 \text { to } 30 \text { years } \\
\text { "intermediaten self- } \\
\text { rating of } \\
\text { or above }\end{array}$ & $\begin{array}{c}\text { Average self- } \\
\text { rating of } \\
\text { "fluent" or } \\
\text { above }\end{array}$ \\
\hline
\end{tabular}

Fig. 1. Participants' profile
This study examines 10 engineering project teams involving 37 students from 11 universities and 1 company. A typical project consisted of a virtual team 4 - 10 Masters or undergraduate students with their supervisors from several universities (in Brazil, Nigeria, Singapore, The Caribbean, and Canada) and an aerospace engineering firm. The virtual team projects comprised of multidisciplinary engineering students participating from a wide range of countries including Nepal, Singapore, The Caribbean, Canada, The United States, Zambia, Rwanda, Burkina Faso, Tanzania, Poland, United Arab Emirates, China, Nigeria, and Brazil. Projects ranged from 4 to 8 months in duration with teams consisting of students from diverse engineering fields, namely mechanical and industrial, civil and transportation, electrical, biocomputational, chemical, biomedical, and computer. Project topics included palm waste utilization, transmission line performance, wildlife tracking, food manufacturing and dam surveillance.

\subsection{Learning Materials and Activities}

The first iteration comprised a 4-week ICM curriculum, delivered through a blend of experiential project-based and collaborative online learning that engaged students in instruction around intercultural communication and global virtual teamwork concepts. The students worked together as a learning community to share perspectives, gain new insights, and apply their newly constructed knowledge within their team projects. This iteration was successful and demonstrated proof-of-concept of a strategy to help students develop global competencies and produced a set of recommendations for improvement [2]. Figure 2 provides an overview of the Intercultural Competency Module (ICM) for the two study iterations.

\begin{tabular}{|c|c|c|}
\hline & $\begin{array}{l}\text { lst Study } \\
\text { Iteration }\end{array}$ & $\begin{array}{l}\text { 2nd Study } \\
\text { Iteration }\end{array}$ \\
\hline $\begin{array}{l}\text { Duration } \\
\text { per session }\end{array}$ & $60 \mathrm{mins}$ & $90 \mathrm{mins}$ \\
\hline $\begin{array}{l}\text { Number of } \\
\text { sessions }\end{array}$ & 4 & 5 \\
\hline $\begin{array}{l}\text { Session } \\
\text { Intervals }\end{array}$ & Weekly & Fortnightly \\
\hline $\begin{array}{l}\text { Total } \\
\text { learning }\end{array}$ & 4 weeks & 9 weeks \\
\hline $\begin{array}{l}\text { Evaluation / } \\
\text { Assessments }\end{array}$ & $\begin{array}{c}\text { Pre-class and } \\
\text { post-class } \\
\text { surveys, Polls }\end{array}$ & $\begin{array}{c}\text { Pre- and post- } \\
\text { class surveys, } \\
\text { polls, self- } \\
\text { assessment, } \\
\text { knowledge } \\
\text { quizzes and } \\
\text { surveys }\end{array}$ \\
\hline
\end{tabular}

Fig. 2. Overview of ICM for the two studies 
The second iteration was a 9-week ICM curriculum, built on successful elements of the first iteration and new elements that were recommended: (1) the addition of a second "intercultural scenario" to enhance student's intercultural communication sensitivities; (2) the inclusion of more opportunities for intercultural experiences; (3) the integration of more active learning techniques to increase students' engagement in the hybrid online learning environment; (5) a module duration increase to accommodate students' learning needs and (4) a module duration time extension to provide more opportunities for students to employ the learning concepts within their virtual team projects between each module. The engineering students participated in guided inquiry discussions aimed at advancing their intercultural competencies through reflection about prior experiences and the co-construction of a community knowledge base. Then, students worked in groups to apply the renewed global perspectives within their engineering projects, thereby improving intercultural communication and decision making in their virtual teams.

\subsection{Data Collection and Analytical Approach}

A mixed method approach was utilized for analysis of data collected across several sources including pre- and post-class survey responses (quantitative), focus group discussion notes (qualitative), inquiry activity responses, and research team observation notes. The collected data were analyzed using basic content analysis method for the survey responses and qualitative content analysis for the group discussion notes. Qualitative content analysis was considered suitable as it supported the exploration of a unique GVT approach, the use of small samples, which has the potential to yield informative results [7] and the study of diverse populations and cultural context [13]. At first, several readings and open coding were conducted on the collected data. Then codes were inductively generated which allowed data analysis to be conducted flexibly to capture key meanings, context, and nuances [10]. Datagrounded categorizes were then created to identify patterns or themes that summarized and described students' voices, perspectives, and learning experiences.

\section{FINDINGS AND DISCUSSION}

\subsection{Pre-survey of students' knowledge and experiences}

At the onset of the ICM, the engineering students responded to a pre-survey that enabled us to gather their background information and gain insights into their prior knowledge and cultural orientation. While many students expressed that they had some international exposure with about $60 \%$ travelling outside their home country more than once, only $7 \%$ had participated in an online multicultural team with international members prior to the program. In addition, though most students were comfortable working in teams with over $80 \%$ indicated their comfort level was either "comfortable" or "very comfortable", only $36 \%$ had prior experience working with multicultural team members from different countries. With regards to English language proficiency, about $60 \%$ rated themselves as "fluent", while a few expressed some concerns about their ability to communicate with team members. Furthermore, while students considered planning (35\%), interpersonal skills $(22 \%)$, technology $(13 \%)$, communication $(13 \%)$ and social interaction $(9 \%)$, as key conditions for effective virtual collaboration, no student recognized the significance of intercultural communication. In general, most of the engineering students did not appreciate the importance of intercultural competence in a global virtual team environment prior to the program.

\subsection{Post-survey of students' learning}

In an exit survey at the end of each module, students expressed that they were highly pleased with ICM, with $96 \%$ rating their experiences as "satisfied" or "very satisfied" as shown in figure 3, and $100 \%$ stating that they would recommend the modules to others. As the ICM curriculum was offered as non-mandatory curricula supports to the students' GVT projects, the students' intercultural learning was not graded. However, students' responses to the focus group discussions were used to evaluate their impression of the program.

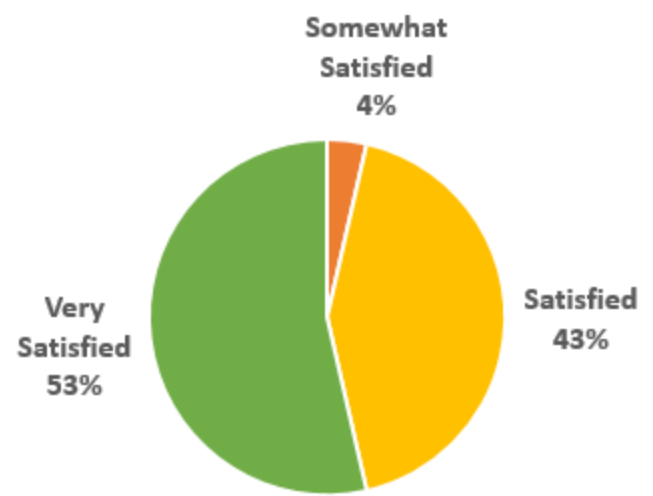

Fig. 3. Students' feedback of the learning experience

\subsection{Focus group discussion of students' learning experiences.}

At the end of the ICM, students were engaged in a focus group discussion and provided open-ended feedback on their intercultural learning experiences and virtual team collaborations. Four distinct themes relevant to the engineering students' achievement and engagement emerged from our coding of students' responses to these items: (a) intercultural awareness and diversity appreciation, (b) project planning and coordination, (c) 
intercultural communication, and (d) social cohesion, trust, and commitment.

\subsubsection{Intercultural Awareness and Diversity}

Appreciation. Students' responses indicated that they appreciated differences in cultural values of team members, recognizing that "we all have different ideals and values that is shaped by our culture", and valuing the diversity of team members (e.g., "we have a good cultural representation in the time[sic]. We respond to solving problem differently"). Thus, "respecting everyone's world view" was important for them as they worked on their engineering projects.

3.3.2. Project Planning and Coordination. MS Teams was utilized by the students to conduct "internal meetings for project discussions" amongst themselves and with their faculty supervisors. However, some students observed that "managing a large team" of about 10 students in a virtual setting had the potential to be challenging, (e.g., "Large group size makes it difficult to track progress \& have efficient meetings"). This challenge was tackled by splitting work activities into "smaller groups / sub- teams" and by encouraging "constant communication with members".

3.3.3. Intercultural Communication and Sensitivities. Students' responses showed that they recognized and appreciated the value of effective communication across cultures and language barriers. They sought to minimize misunderstandings by "recognizing differences $\&$ asking for clarification", striving to "communicate clearly", and making efforts to "respect each other". Some students acknowledged the value of having diverse voices in the decision-making process by ensuring that "all share ideas", and by listening more as depicted by one student's response, "I like to start conversations and listen the point of view from other members".

3.3.4. Social Cohesion, Trust, and Commitment. The student teams made efforts to engage in virtual interactions outside the formal project communication tools (e.g., "recently I and my colleague connected on the whatsApp platform as this will enable us communicate more easily"). These social interactions helped students to earn swift trust within the team as depicted by one student, "we all view each other as trustworthy". They also helped to build a sense of belonging and social cohesion in the team that supported their virtual team collaboration activities. For instance, one student highlighted that, "in conflicting issues, we have ensured that every opinion is heard then we decide as a team what is best". These enabled the students to remain committed to the team goals as highlighted by one student: "team members are very proactive, efficient in whatever tasks they are assigned; they are also very keen on solving problems".

\section{CONCLUSION AND SIGNIFICANCE}

Results from the two iterations showed that students' cultural orientations at the start of the GVT program were similar as both cohorts did not have an appreciation of intercultural competencies prior to the ICMs. Similarly, at the end of the ICM curriculum, students in both iterations were highly satisfied with the program. In addition, we observed that similar themes emerged from our analysis of the focus group discussion notes for the two studies. Hence, our study showed that a blend of the Intercultural Competency Module (ICM) and the global virtual team projects was a successful approach for engineering students to learn to communicate with peers from diverse cultures, collaborate to create sustainable solutions for authentic global engineering projects and develop a global mindset that can help them make culturally responsible decisions. Taken together, our results suggest that the GVT program helps engineering students gain international experience, improve their global perspectives, and become effective international collaborators. This study is significant as it provides evidence of a successful strategy that can be used to introduce international experiences and global perspectives into engineering programs. It also demonstrates a feasible approach for incorporating international research experiences into higher education institutions. Finally, the study serves to promote the internationalization of engineering education while adding to the body of research on the use of global virtual teams to support a sustainability mindset in engineering education.

\section{Acknowledgements}

This research was supported by the University of Toronto's Faculty of Applied Science and Engineering's Deans Strategic Fund and the 2020 Engineering Education Teaching Fellowship Program. Human protocol ethics approval including written informed consent from the participants was obtained for this study.

\section{References}

[1] Alex Koohang, Liz Riley, Terry Smith, and Jeanne Schreurs, "E-Learning and Constructivism: From Theory to Application", Interdisciplinary Journal of E-Learning and Learning Objects, vol. 5, no. 1, pp. 091-109, 2009. Available:

https://www.learntechlib.org/p/44824/article_44824.pdf. [Accessed 8 January 2021]. 
[2] Anuli Ndubuisi, Elham Marzi, and James Slotta, CrossCultural Virtual Team Projects: International Virtual Engineering Student Teams. In Developments in Virtual Learning Environments and the Global Workplace. IGI Global. IGI Global, 1AD. 2021.

[3] Faculty of Applied Science \& Engineering, By The Numbers 2020, University of Toronto. 2020. Available: https://www.engineering.utoronto.ca/files/2020/09/ar2020 internal finalrev web.pdf. [Accessed 10 January 2021].

[4] Gisela Cebrián, Merce Junyent and Ingrid Mulà, "Competencies in Education for Sustainable Development: Emerging Teaching and Research Developments", Sustainability, vol. 12, no. 2, p. 579, 2020. Available: https://www.mdpi.com/journal/sustainability/special_issues /Competencies_ESD. [Accessed 7 January 2021].

[5] Institute of International Education, Report on International Educational Exchange, Opendoors, 2019.

[6] Institute of International Education, 2020 Fast Facts, Opendoors. 2020

[7] James Drisko and Tina Maschi, Content Analysis. Oxford University Press, 2015.

[8] James Slotta, Rebecca Quintana, and Tom Moher, "Collective inquiry in communities of learners." International handbook of the learning sciences, pp. 308-317. 2018

[9] Lidia Alexa, Maier Veronica, Șerban Anca, and Craciunescu Razvan. "Engineers Changing the World: Education for Sustainability in Romanian Technical Universities-An Empirical Web-Based Content Analysis", Sustainability, vol. 12, no. 5, p. 1983, 2020. Available: 10.3390/su12051983 [Accessed 8 January 2021].
[10] Margarete Sandelowski, "Whatever happened to qualitative description?," Research in Nursing \& Health, vol. 23, no. 4, pp. 334-340, 2000,

[11] Martha Cleveland-Innes, Randy Garrison, and Norm Vaughan, Implications for distance education and beyond. In M. G. Moore \& W. C. Diehl (Eds.), Handbook of Distance Education, pp. 169-181, Routledge, 2018

[12] Mirka Martel. "COVID-19 EFFECTS ON US HIGHER EDUCATION CAMPUSES. From Emergency Response to Planning for Future Student Mobility." Institute of International Education. 2020, Available: https://acasecretariat.be/newsletter/from-emergency-response-toplanning-for-future-student-mobility/ [Accessed 5 March 2021].

[13] Mo Yee Lee and Amy Zaharlick. Culturally Competent Research: Using Ethnography as a Meta-Framework. Oxford University Press.

[14] National Academy of Engineering, Grand Challenges for Engineering: Imperatives, Prospects, and Priorities: Summary of a Forum. National Academies Press, 2016.

[15] National Academy of Engineering, NAE Grand Challenges for Engineering. 2008.

[16] Sarah Rajala, "Beyond 2020: Preparing engineers for the future", IEEE, (Special Centennial Issue), 100, pp. 13761383. 2012

[17] United Nations Educational, Scientific and Cultural Organization, "Education and the Search for a Sustainable Future", UNESDOC Digital Library, 2009. 